\title{
INDICATORS OF SUSTAINABLE DEVELOPMENT FOR CULTURAL LANDSCAPES: FILM SCENERIES AND CULTURAL HERITAGE
}

\author{
ESTHER SAN SEBASTIÁN POCH ${ }^{1}$, URTZI LLANO-CASTRESANA ${ }^{1} \&$ ANDER DE LA FUENTE ARANA $^{2}$ \\ ${ }^{1}$ Department of Engineering in Bilbao, University of the Basque Country, UPV/ EHU, Spain \\ ${ }^{2}$ Department of Architecture in San Sebastian, University of the Basque Country, UPV/ EHU, Spain
}

\begin{abstract}
Cultural tourism is a good way to promote and safeguard the cultural heritage of a place. Cultural tourism includes film tourism, which consists of those places where cinema and TV productions have been shot. This can contribute to valuing the local cultural heritage or, by contrast, to reifying it and, consequently, to the loss of its authentic and its identity. In the following article we propose a system of indicators of sustainable development in order to evaluate and guarantee long-term sustainability in those places identified with traditional cultural heritage and that have become film sceneries. Once the study cases have been identified, the cultural landscapes that are going to be evaluated will be defined. To do that, we will identify and select the film sceneries according to the degree of conciliation between these and cultural heritage. The impact on society of the cinema productions will also be taken into account. The union amongst the film sceneries through the local heritage (built heritage, landscape heritage, etc.) will result in one or several cultural landscapes where the balance between the welfare of the host society and the tourism demands will be evaluated. To put into practice the following methodology, the Historic Centre of Peñíscola has been chosen to be evaluated. This was declared a Historic-Artistic Site in 1972 and has a long history as film scenery, which has contributed to its valuation and has brought it closer to the audience.
\end{abstract}

Keywords: film tourism, film sceneries, cultural heritage, cultural landscapes, indicators of sustainable development, degree of conciliation.

\section{INTRODUCTION}

Cultural tourism is said to be "that form of tourism whose object is, among other aims, the discovery of monuments and sites" [1]. It is a highly demanded form of tourism and, because of this, it is a good way to value, promote and, consequently, preserve the traditional cultural heritage [2, p. 1] as long as it is correctly managed. However, the relation between cultural heritage and cultural tourism is constantly evolving. It is always adapting to the new tourism tendencies and demands, which are farther and farther from the points of interest of the traditional and rooted cultural heritage and closer to other components of a global and shared collective imagination such as gastronomy, sports or cinema. In the following article we aim to focus on and look in-depth into the latest, the cinema. More specifically, we aim to look in-depth into the film sceneries and how they influence the cultural heritage.

Film sceneries are said to be places where cinema productions have been shot and that nowadays have become an important point of attraction for tourists. Movie-induced tourism which encourages tourists to visit those film sceneries is known as "Film Tourism" [3]. Film tourism can be beneficial in promoting tourism destinations and their local heritage.

However, the audience seems to feel more attracted to those imaginary worlds created by cinema and TV rather than by the authenticity of the sites and their monuments. These sceneries become part of the cultural legacy of a site, being identified with the latest. Due to this, traditional cultural heritage is being relegated to a second place and, in some cases, it is being deprived of its true identity, being led into reification. In addition, this new tourist 
product encourages a new mass of tourists to come to these locations, for which they may not be prepared, making changes in their traditional lifestyles in favour of tourism demands. In short, they change their identity.

A constant and dizzying growth of tourism demands, among which film tourism is included, justifies an increased interest for the definition of systems of indicators applied to tourist destinations as a means of the evaluation of the degree of sustainability. In this article, a system of indicators of sustainable development is proposed in order to evaluate both the degree of sustainability of those destinations identified with a traditional cultural heritage and their future prospect, especially after the shooting of one or a large range of cinema productions that have had some impact in society. The indicators must provide information regularly and must be reviewed from time to time, so that a long-term sustainability can be guaranteed.

A model of sustainability intends to guarantee the balance between tourism demands and the welfare of the host society by respecting the latest's socio-cultural authenticity, making a good use of its environmental resources and creating activities that provide sustainable economic benefits to its agents in the long-term [4].

There is a great variety of systems of indicators and all of them consist of two parts: a selection and an evaluation criteria for indicators. With regard to the former, we will take the selection criterion proposed by the UNWTO and documented in the book "Indicators of Sustainable Development for Tourism Destinations. A Guide Book" [5] as a reference. According to UNWTO, the selection criterion is divided into two phases: the identification of tourism destinations, their attractions and the risks uncontrolled tourism would involve and the selection of the indicators [5, pp. 28-30, 43-49]. The latest can be approached from two perspectives: a selection of the indicators through which the right questions could be asked or the identification and selection of the questions for which we would need to request information and validate the sources of information.

Once the indicators have been selected, we aim to evaluate them. However, these are many and diverse, measurable with a large range of metrics $\left(\mathrm{m}^{2}, \%\right.$ of deterioration, etc.) or not measurable. The number of indicators must be reduced and a unit of measurement must be stated. For these reasons and because we will partly be based on the following concept, we will go for the "synthetic indicators".

The use of synthetic indicators allows us both to reduce the number of indicators without reducing the volume of information and to quantify what is not quantifiable (degree of satisfaction, the degree of sustainability, etc.). The analyst is responsible for the election of indicators and the evaluation criterion. "He will standardise and ponder the information, removing some of the subjective aspects, which are part of the synthetic measure and inherent to analyst, as he is involved in the subject of study" [6]. In other words, there is no method better than another to construct a synthetic indicator. It is only the analyst's election of an aggregation process based on the needs and concerns of the study they are carrying out. In short, we will do the same with the system of indicators proposed.

\section{A JUSTIFICATION FOR THE METHODOLOGY}

However, why do we need a new system of indicators? Why don't we make use of those already existing? As with the existing ones, we will make use of an aggregation process so that we can summarise the selected indicators in three groups (synthetic indicators), each of them corresponding to each of the indicators of sustainable development (socio-cultural, environmental and economic). But unlike these, we don't search for neither the quantification of what is not quantifiable, nor the suppression of the subjective character 
implied in the questions of the study and, therefore, in their indicators and evaluation method. Not because it can't be done, but because it should not be done.

There are several factors which are constantly changing and evolving such as the ones related to culture. "Culture is one of those concepts that is said to be migrant, which means its meaning is permanently changing in both a spatial and timeframe. The subjectivities of culture's content are as diverse as the societies and the individuals that develop and value a particular cultural expression" [7]. That is why we question the viability of the existing systems of indicators and their application to diverse fields. And for the same reasons, the system of indicators we propose is more qualitative, applicable to all those sites which are concerned with the preservation of their traditional cultural identity due to an uncontrolled film tourism. However, each site will always keep its single and subjective character, which means all the study cases shouldn't be valued according to the same parameters.

In order to carry out the following methodology, we must ask ourselves how the film sceneries are chosen. The confection of the diverse sceneries starts with elements that build the site such as the built heritage, the landscape heritage, etc. These ones highlight the individual, authentic character of the site, of an added value that makes it different from the rest and therefore, more accurate and suitable for the argument and the setting of the cinema productions. Such components of the site create a link between reality and fiction, making possible a certain degree of conciliation between them, without the latest overshadowing the former. The heritage value of a site plus the value added by the cinema equals a large range of study cases, each of them unique and unrepeatable.

From now on, we shall start with our proposal for a system of indicators. Apart from the already mentioned characteristics of the sites we are about to evaluate, we will tighten the circle by focusing on small or medium-sized coastal towns, with the beach and the sun as other tourist attractions, which means we are focusing on sites which should be lightly used to tourism. For a better understanding of the methodology and to prove its viability, a study case will be exposed. In this case, the Historic Centre of Peñíscola has been chosen. This was declared a Historic-Artistic Site in 1972, has great experience in film sceneries that dates back to the beginning of the $20^{\text {th }}$ century and that has contributed to promote both its built and landscape heritage at international level.

\section{A PROPOSAL OF A METHODOLOGY}

The following methodology will consist of three phases: the definition and delimitation of the evaluation scope or cultural landscape; the selection of the items and the indicators of sustainable development (socio-cultural, environmental and economical) and their evaluation.

\subsection{The definition and delimitation of the evaluation scope}

The first phase is subdivided into four sections: the definition of the tourist destination, the identification of the film sceneries and both the cultural and natural assets that compose them, the visual perception of the cultural landscapes from other points of view and the final composition of the cultural landscapes to be evaluated.

\subsubsection{The definition of the tourist destination}

To define the tourist destination, we will make use of the classifications documented in the already mentioned "Indicators of Sustainable Development for Tourism Destinations. A Guide Book". Amongst all the classifications, the ones that best fit the type of tourist destination to be evaluated are: "Small and Traditional Communities" [5, pp. 281-282], 
"Built Heritage Sites" [5, 99. 278-281] and "Urban Tourism" [5, pp. 282-286], referring to those sites identified with a single built heritage and for which it is worth visiting. The "Coastal Zones" [5, pp. 247-251], the "Beach Destinations and Sites" [5, pp. 251-253] and the "Natural and Sensitive Ecological Sites" [5, pp. 263-268] provided with a great variety of highly demanded ecosystems for both local residents and tourists will be included.

Referring to the Historic Centre of Peñíscola, this is composed of the Old Town or a residential complex surrounded by Middle-Aged and Renaissance walls and its immediate surrounding known as the "Influence Area". Besides the walls, inside the Old Town stand out other singular buildings such as the Castle of Peñíscola, the Parochial Church or the Church "La Ermitaña".

The Old Town is located on a natural enclave (limestone rock) that was originally linked to the land via a sandy isthmus that little by little has been affected by the continuous works on the extension project of the port at the southern side of the site or by the progressive construction of residential buildings for tourists at the western side of the site or alongside the isthmus that started in the 40s. These works have contributed to the loss of identity and the environmental degradation of the site, since the sandy isthmus has partly disappeared.

\subsubsection{The identification of the film sceneries and both cultural and natural heritage assets that compose them}

Once the tourist destinations have been selected, we will proceed to the identification and the selection of the film sceneries and with that, the identification of both cultural and natural assets that compose them. Firstly, a list of all the cinema and TV productions that have been shot in the selected tourist destinations will be made. However, there may be a lot of films or TV series in that list and their storylines and, consequently, their settings may be very different from each other. For these reasons, a selection criterion of the cinema productions will be set. This will be based on the following two criteria: the degree of conciliation amongst the elements that make up the site (architectural, urban, landscape, etc.) and the setting of the cinema productions; the degree of appreciation of the audience at different levels (local, national, international level). The former will highlight the individual character of each of the tourist destinations.

The film history of Peñíscola dates back to the first decade of the $20^{\text {th }}$ century and, nowadays, remains firm. Its long list points out films such as "Calabuch" (Berlanga, L.G., 1956), "El Cid" (Mann, A., 1961), "Todos eran Culpable" (Klimovsky, L., 1962) or the more recent and popular "Game of Thrones" (2011-2019). Due to the built and landscape characteristics of the Historic centre of Peñíscola, we will opt for historical cinema productions that best fit the aforementioned constructions. Having taking into account the degree of conciliation of both the film sceneries and the characteristics of the site and the degree of acceptance of the diverse cinema productions, we have finally opted for the following study cases: "El Cid" (1961) [8] and "Game of Thrones" (2015) [9]. The study cases will be evaluated separately.

After identifying and selecting the final cinema productions, we will have to identify the film sceneries and the built or landscape heritage that makes them up. To do that, a deconstruction process through which we will decompose each film scenery by identifying and separating the cultural goods from the added decorations (stage decorations, special effects in films) will be developed. In other words, we will separate reality from fiction. To begin with, we will have to start with a brief description of the story and the setting of the films, so that we can figure out what is real and what may have been added.

For the shooting of the film "El Cid", the Historic Centre of Peñíscola was converted into the city of Valencia in the 11th century. Although this city was founded by the 
Romans, in the 11th century this was under the Arab's reign, which means there must have been perceived the Arab influence in the streets. With regard to "Game of Thrones", the Renaissance walls of Peñíscola became the walls of a fictional town called "Meeren". Although it seems to be a medieval town, there is not much information about it.

Later, we will then identify all the film sequences where the film sceneries appear. We will have to resort to the films or TV series themselves and capture all the frames (images) of which the sequences consist. Each sequence will be labelled with the title of the film or TV series, the season and the chapter (in case it is a TV series), a brief description of the scene and the minute of the projection.

Once all the sequences have been identified, we will identify the film sceneries. Therefore, we will make use of a location plan with different scales, according to the number and the area of the film sceneries, the context to which they belong (different sites, their monuments, etc.), the level of detail, etc.

In the case of the film "El Cid", a total of seven sequences organised in three different film sceneries have been identified: the Ramp of Felipe II and its immediate surroundings, the Gate of Sant Pere and the Northern Beach, with the Old Town of Peñíscola as a backstage. Referring to "Game of Thrones", during the sixth season, a total of four sequences distributed over three chapters and organised in two film sceneries have been found. The film sceneries are the already mentioned Ramp of Felipe II and the Parque de la Artillería. As we can observe, the same site can become several different film sceneries (Fig. 1).

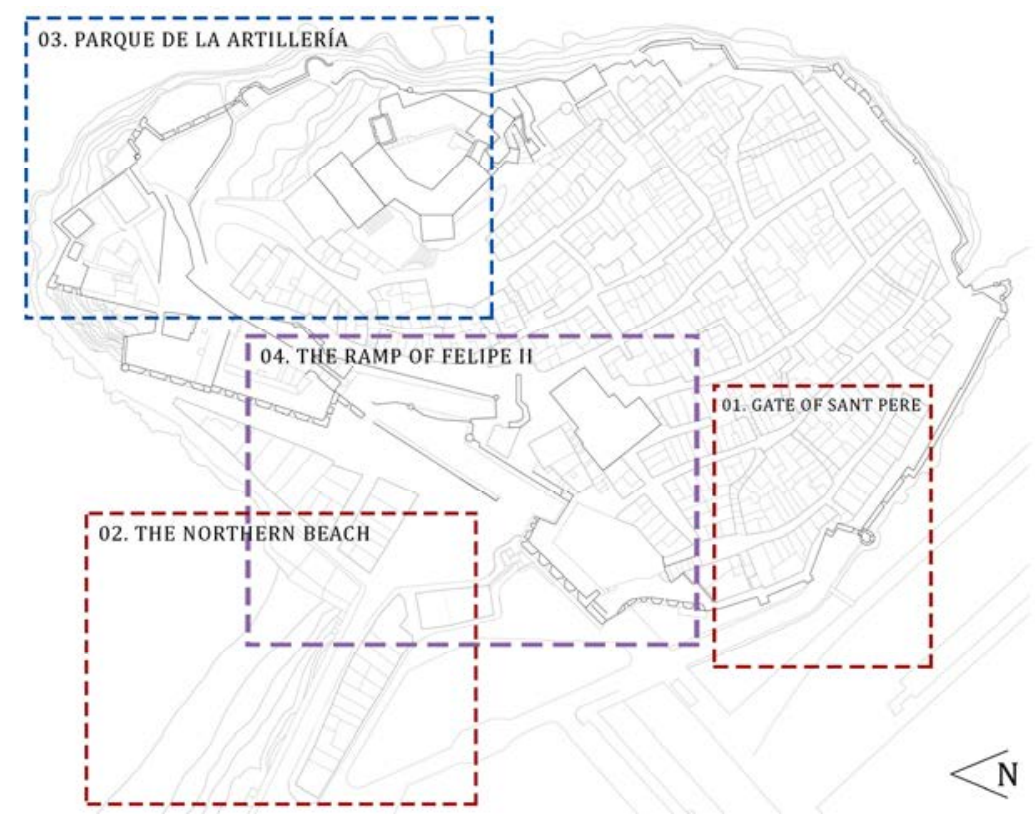

Figure 1: Location plan of the film sceneries. "El Cid" (in red), "Game of Thrones" (in blue), film sceneries in common (in purple).

After delimiting the area of the film sceneries, we will keep track of the film sequences over the location plan and, if it was possible, in situ. On the same plan, we will draw the 
storyline of the relevant sequences, indicating the continuity or discontinuity of them. Along the film routes, the approximate location and orientation of the film cameras will be set. In addition to the film routes, some frames (images) of the film sequences will be included. The images will be organised chronologically and each of them will refer to one of the cameras set on the plan (Fig. 2). The inclusion of the images will help us in both the comprehension of the film sequences on the plan and in situ and the total space captured by the cameras and its depth of field. The images will be directly cut out of the films or TV series, so that the images can maintain the length-to-width relationship. Each of the sequences will correspond to one plan.

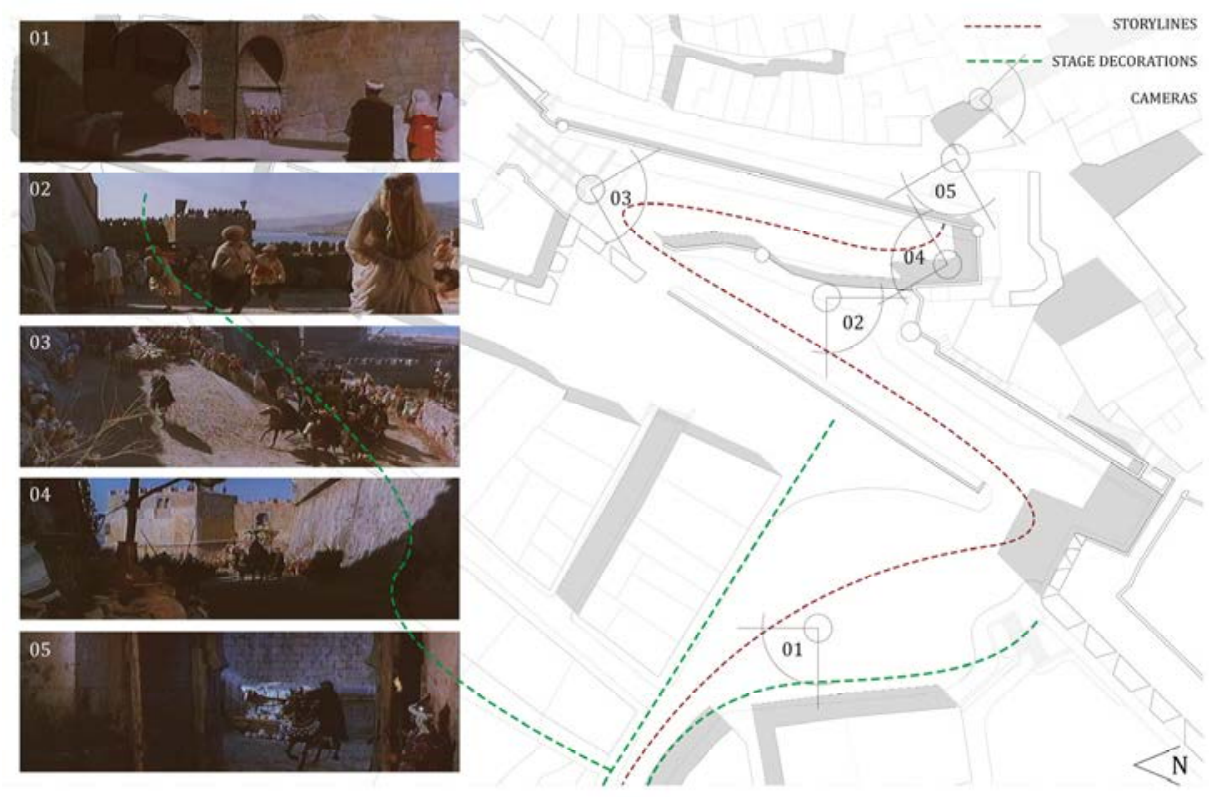

Figure 2: The Ramp of Felipe II and its immediate surroundings. Film sequence "Conspiracy”, (“El Cid”).

On the very same location plan, we will identify and indicate the heritage goods that compose the film sceneries (Fig. 3). In case that more than one sequence or even more than one cinema production had been shot in the same scenery, we could be dealing with information overload and we would need to resume it and documented in just one plan by keeping those cameras that would give us as much information as possible and getting rid of the rest. The cameras orientated to a clear stage decoration will be temporally rejected. Once all the heritage goods in the film sceneries have been identified, they will be located on the same location plan or on another plan at a lower scale, so that we can perceive the total area of the film sceneries.

Amongst the immovable goods, we can differentiate between cultural built heritage and the natural heritage [2, p. 2]. The built heritage is divided into two groups: the buildings or the monumental constructions plus their immediate surroundings and the open urban spaces plus the buildings around them that delimitate their area. For the collection of the most relevant data on both cultural and natural heritage like the heritage value of these, their 
degree of protection, the state of preservation, etc., we will make use of local regulations such as Special Protection Plans for Heritage, Catalogues, Special Plans for both Internal and External Reform, etc. We will also resort to national and international regulations.

Despite the fact that both cinema productions were shot in different film sceneries, they share one of them: the Ramp of Felipe II and its immediate surroundings. It consists of the Batteries of the Oblivion, Calvary and Santa María, the Balcony of Pilatus, the residential complex on the west face of the hill and the Old Town as a whole in the distance.

As we have identified the heritage goods and have documented them on the previous plans, we will do the same with the stage decorations and the special effects additions in films (Fig. 3). As we have mentioned before, in the film "El Cid", the Historic Centre of Peñíscola became the city of Valencia in the 11th century, which was under the Arab reign and for which certain type of decorations such as Arab arches, Horseshoe arches, etc. had to be added. In addition, a fake wall has been detected alongside the sandy isthmus and in the west face of the hill, so that the residential complexes for tourist that have been built since the decade of the 1940s were hidden. With regard to "Game of Thrones" there have been detected more special effects additions in the sceneries rather than stage decorations. Among these, a great pyramid at the top of the hill has been detected.

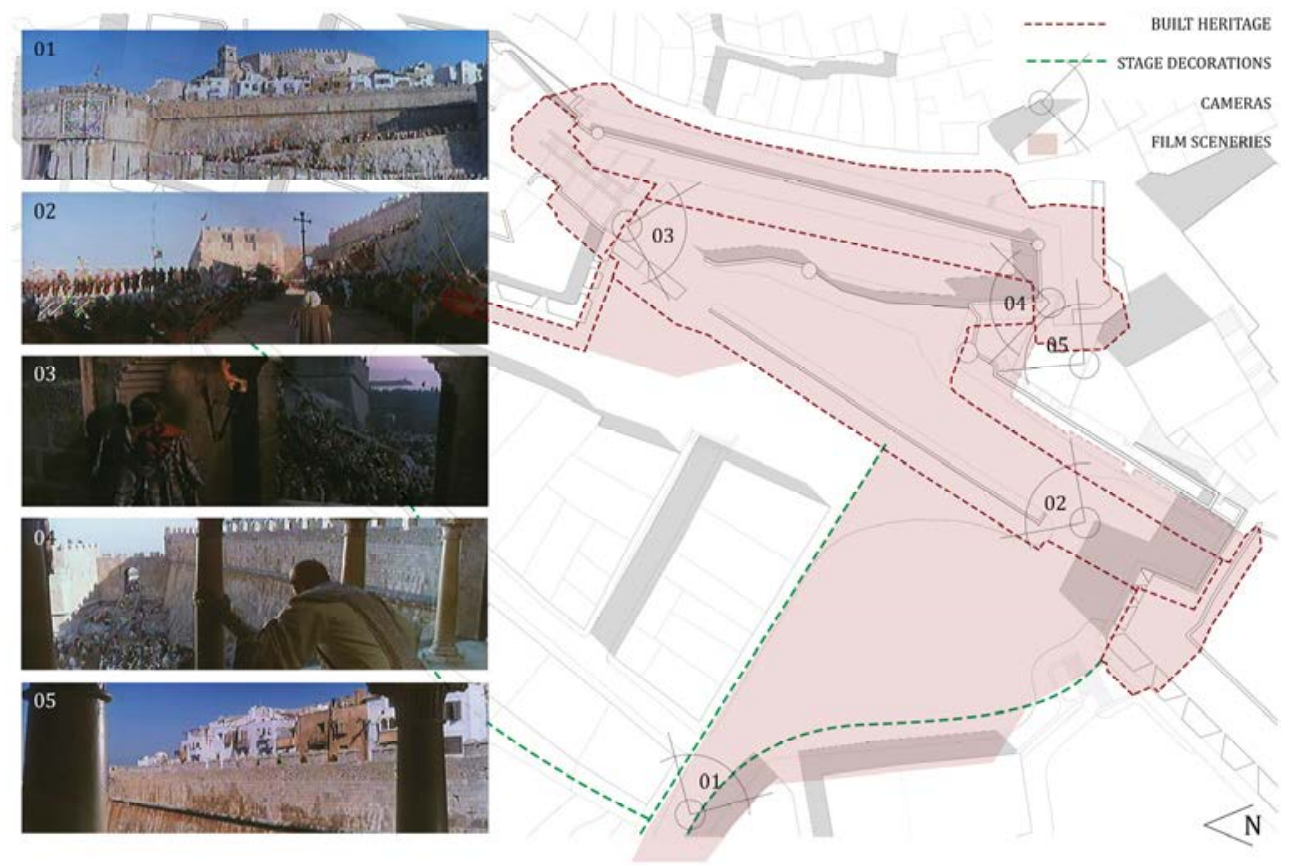

Figure 3: The total area of the film scenery: the Ramp of Felipe II and its immediate surroundings. Built heritage (the Ramp of Felipe II (1), (2), the Batteries of the Oblivion (1), (2), of the Calvary (1), (4), (5) and of Sta. Mary (3) and stage decorations. "El Cid". 
3.1.3 The visual perception of the cultural landscapes from other points of view Once the process of deconstruction is over, we will continue with the definition of the cultural landscape. The following section is entitled "The visual perception of the cultural landscapes from other points of view" and proposes a perception of the previously drawn, but unfinished cultural landscape from different paths of civilian transit in the distance. The perception of the landscapes from other points of view will provide us with a more global and coherent vision of them, standing out items or other elements not present in the film sceneries, but highly prominent in the landscapes. For these reasons, these items must be included in the final landscape.

3.1.4 The final composition of the cultural landscape

To end the definition of the cultural landscape, we will have to collect all the previous plans and superimpose them into one single plan, so we can visualise the final landscape (Fig. 4).

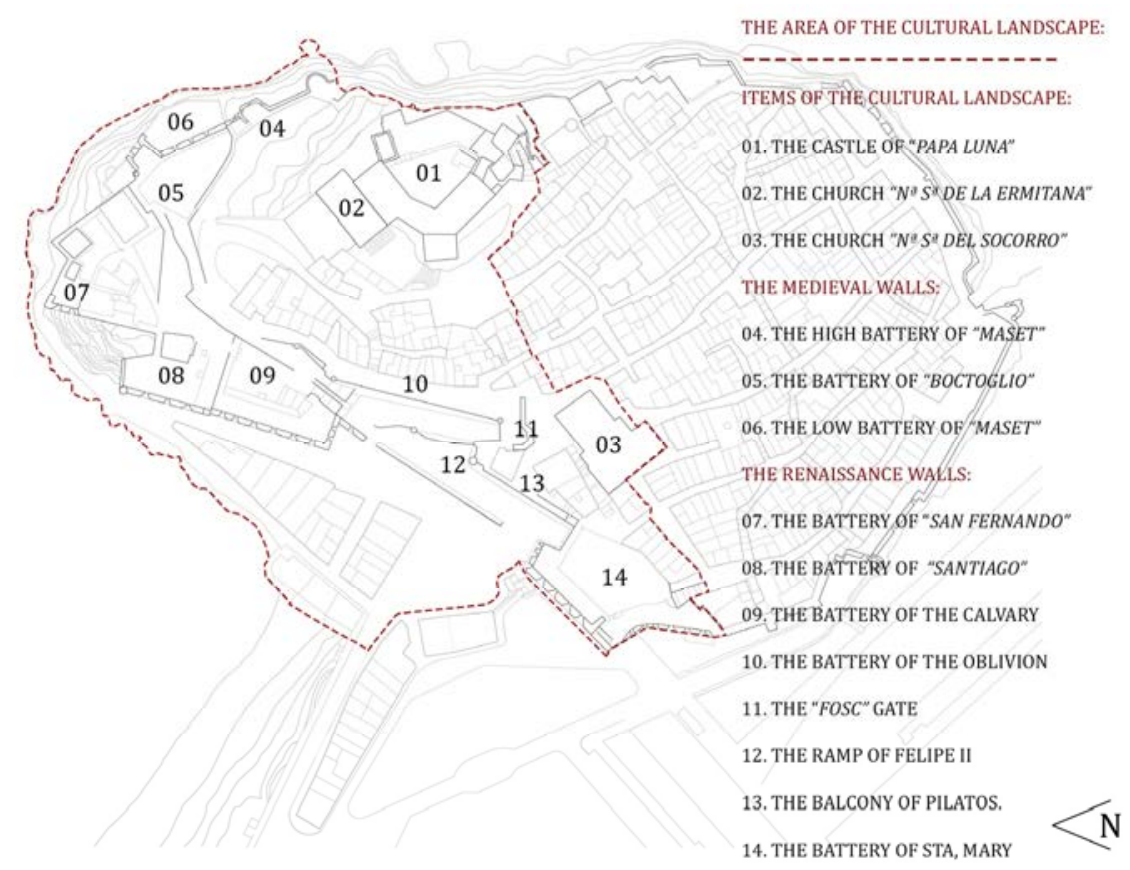

Figure 4: The final composition of the cultural landscape and all the items that compose it.

\subsection{The items and indicators of sustainable development}

Once the cultural landscape has been defined, we will ask the questions that need to be answered and express our concerns that need to be solved and, consequently, the indicators that support them. To do this, firstly, we will appeal to the previously mentioned "Indicators of Sustainable Development for Tourism Destinations. A Guide Book", where a large range of concerns according to the diverse tourist destinations have been documented [5, pp. 58-59, 76-82, 91, 112-113, 124-125, 147]. Some of these will be selected and collected in a first list. Later, we will generate a second more personal list related to the film sceneries and how they can influence the cultural heritage of the tourist destinations. 
The study of the two lists will result in a final selection of questions and in the indicators and the sources of information.

After having studied both lists, the final questions will be "protecting and promoting the cultural value of the site", "tourism as a contributor to socio-cultural and environmental changes" and "culture and economic development of a site".

3.2.1 Protecting and promoting the cultural value of a site

So that we can evaluate the first question, we will appeal to the already mentioned "degree of conciliation" amongst both cultural and natural heritages and the film sceneries. In case there were more than one film scenery in the evaluation scope or cultural landscape, it would be interesting to create a link through the local heritage resulting in one or several cultural itineraries (some may exist) that promote both the traditional cultural tourism and film tourism. These cultural itineraries and indicators will be called "Structures of cultural interest. Film sceneries and Cultural heritage".

\subsubsection{Tourism as a contributor to socio-cultural and environmental changes}

The second question will be evaluated through the following indicators: "The satisfaction of the basic and the complementary demands alongside the structures of cultural interest" and "The visual impact management of the cultural landscape". The former aims to evaluate the degree of satisfaction of both the basic (transport infrastructures, accommodation, catering) and complementary (entertainment, leisure, etc.) demands alongside the existing or non-existing cultural routes. The latter, however, intends to evaluate the (urban, aesthetic, etc.) evolution and the state of preservation of the cultural landscapes throughout the cultural routes or in the distance, referring to the points of view proposed in the previous section "Visual perception of the landscape" and others.

To study the evolution and development of the cultural landscapes, we will have to resort to local regulations such as urban planning frameworks, Special Protection Plans for Heritage, Special Plans for Reform, photographs, local testimonies, etc.

Another factor to take into account is the human factor, in other words, the presence of tourists in the host communities and how they affect the day to day life of the local residents. The existence or non-existence of Tourism Promotion Plans, satisfaction surveys for inhabitants and tourists, etc. will be considered and valued.

\subsubsection{Culture and economic development of a site}

To evaluate the third and last question, we will make use of these two indicators: "Tourist offer", referring to all those cultural activities offered by the host communities and "Use Intensity" before and after the shooting of a film or TV series.

3.3 The application of the methodology. The evaluation of the indicators of sustainable development

Although the number of questions has been reduced to three and, with these, the number of indicators, we need to reduce them a little bit more before proceeding to the final evaluation. With regard to the already mentioned "synthetic indicators", whose main function consists of reducing the number of indicators without reducing the quantity and the content of the information, we aim to reorganise and, thanks to that, to simplify all the indicators written above into two groups: "Structures of cultural interest: Cultural Heritage, Cinema and Cultural Tourism" and "Basic demands: the uses of the buildings and open spaces". 
3.3.1 Structures of cultural interest: Cultural heritage, cinema and cultural tourism

The following section reunites the following indicators: "Structures of cultural interest. The Degree of Conciliation among both cultural and natural heritages and film sceneries", "Tourist Offer. Cultural Activities" and "The Visual Impact Management". The latest indicator will be part of both groups. In this case, it will refer to development and the state of preservation of the cultural landscapes.

\subsubsection{Basic demands. The uses of buildings and open spaces}

Besides the indicator entitled "The satisfaction of the basic and the complementary demands alongside the structures of cultural interest", this section will newly include "Visual impact management", based on the presence of tourist in the diverse destinations and how they influence the day to day life of the local residents.

All the information obtained will be compiled in a series of tables and graphically represented in one single plan (Fig. 5). This plan will include the total area of the evaluated cultural landscape, its respective structures of cultural interest (new ones and already existing ones) and its tourist offer, the buildings and public spaces intended for leisure (museums, theatres, etc.), accommodations, catering and the transport infrastructures. Down below, the final plan of the cultural landscape of the Historic Centre of Peñíscola will be shown.

\section{CONCLUSIONS AND FUTURE PROSPECTS}

On the plan represented in Fig. 5, a total of three different structures of cultural interest are shown. Two of them (the Monumental Route in yellow and the Historic-Artistic Route in orange) already existed and the third one is a new one and it is drawn in red. This one corresponds to the film sceneries where both the film "El Cid" and the more recent TV series "Game of Thrpones" were shot and the union amongst them through the built heritage of the site, in the case, the Renaissance walls on the west face of the Old Town of Peñíscola. We can emphasise several connection points among the three cultural routes such as the walls themselves, the Battery of Santa Ana, the Ramp of Felipe II and the Parque de la Artillería, which lead us to the conclusion that it is a high degree of conciliation between the local heritage and the film sceneries.

Each of the structures of cultural interest is organised alongside a path mainly intended for pedestrians. Due to a sloping ground and, consequently, to the staggering of the walled complex, the use and the vehicle parking are restricted to some points, such as the Battery of Santa Ana and the Ramp of Felipe II, as it can be observed in Fig. 5. For these reasons and because of the existence of local regulations that regulate the degree of intervention in the Historic Centre of Peñíscola, the degree of protection of both the individual and collective constructions and of the aesthetic of the landscape is high. On the plan, the human factor is not reflected because there are many uncertainties and indicators to be evaluated (the annual number of tourists, in both the high and the low seasons, the occupancy of tourist accommodations, etc.). However, it is essential that a continuous follow-up of these and other indicators that can contribute to destabilize the host communities' lifestyles and the image of the landscapes is undertaken.

In conclusion, we can assert that the degree of sustainability of the Historic Centre of Peñíscola is high and that the proposed methodology has proven to be right and accurate for the evaluation of this type of tourist destinations. However, it is convenient to apply this methodology to other study cases, whether they are similar to the Historic Centre of Peñíscola, with a long film career, or those study cases at the very beginning of their film 
career. This will allow us to obtain more detailed information about the viability of the proposed methodology and its weaknesses, contributing to its improvement and perfection.

In addition to this, the proposed indicators must provide information regularly and must be revised from time to time or even complemented with others that were not proposed originally, but that could help complement the obtained data and guarantee a long-term sustainability of the tourist destinations.

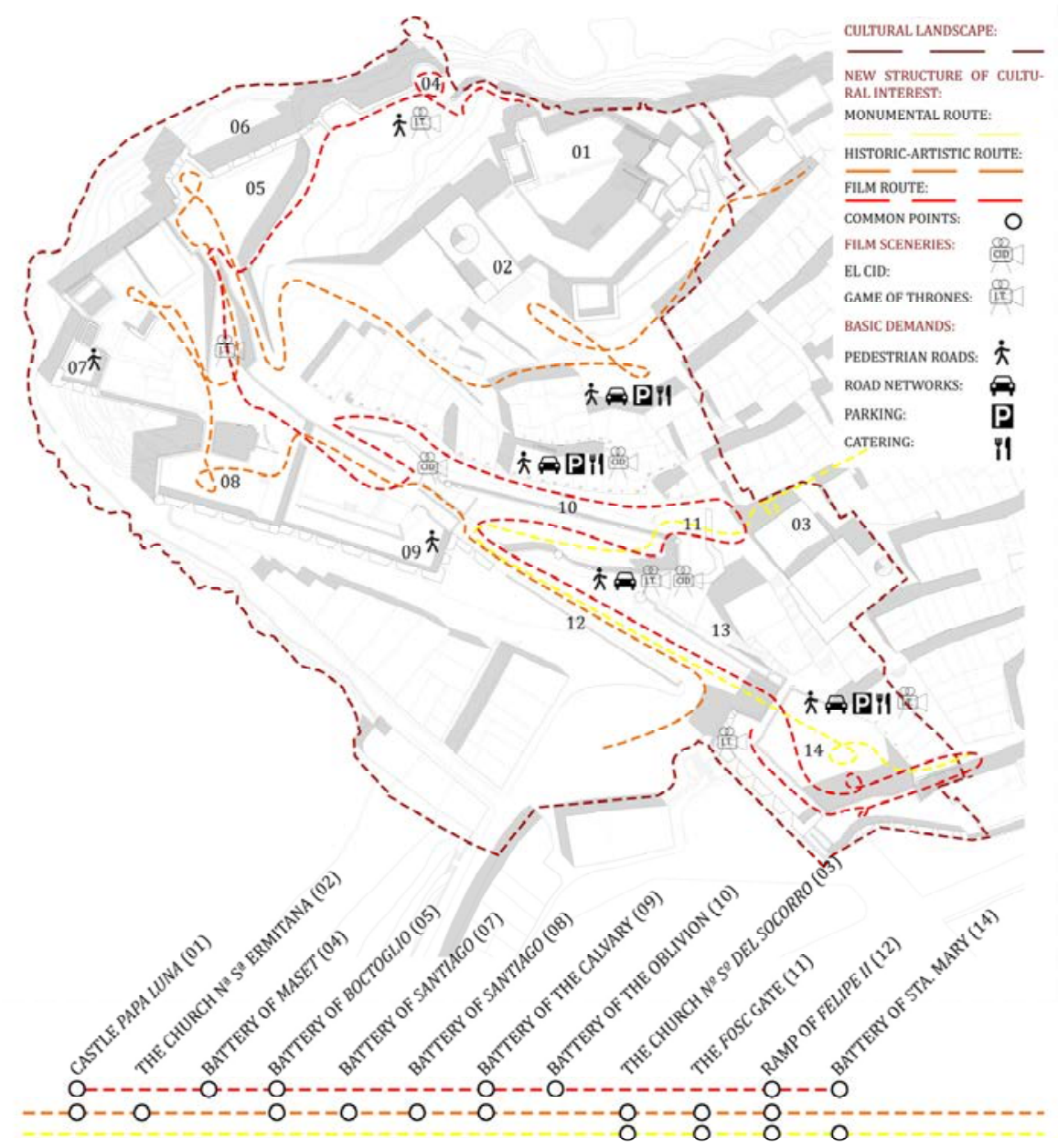

Figure 5: Final plan: cultural landscape. Evaluation of indicators: structures of cultural interest, cultural heritage, cinema and cultural tourism and basic demands.

\section{REFERENCES}

[1] ICOMOS, Charter of cultural tourism. Seminar on Contemporary Tourism and Humanism, pp. 1-3, 1976.

[2] UNESCO, Convention for the protection of the world cultural and natural heritage. pp. $1-2,1972$.

[3] Evans, M., Plugging into TV Tourism, Insights, pp. 35-38, 1997. 
40 Structural Studies, Repairs and Maintenance of Heritage Architecture XVI

[4] UNED, UNWTO, Making tourism more sustainable - A guide for policy makers, pp. $11-12,2005$.

[5] Indicadores de desarrollo sostenible para los destinos turísticos - guía práctica, UNWTO, 2005. www.ucipfg.com/Repositorio/MGTS/MGTS14/MGTSV-07/tema2/ OMTIndicadores_de_desarrollo_de_turismo_sostenible_para_los_destinos_turisticos. pdf. Accessed on: 4 May 2019.

[6] Blancas Peral, F.J., González Lozano, M., Guerrero Casas, F.M. \& Lozano Oyola, M., Indicadores sintéticos de turismo sostenible: una aplicación para los destinos turísticos en Andalucía. Revista electrónica de Comunicaciones y Trabajos de ASEPUMA, 11, pp. 85-118, 2010.

[7] Caraballo Perichi, C., Volviendo a los Indicadores. La Cuantificación de los Criterios Patrimoniales ¿Un Objetivo Alcanzable? Crónica de un Ejercicio Colectivo en el Análisis de casos Mexicanos de la Lista del Patrimonio Mundial. El Paisaje Histórico Urbano en las Ciudades Históricas Patrimonio Mundial: Indicadores para su Conservación y Gestión, vol. 1, Instituto Andaluz del Patrimonio Histórico, pp. 58-69, 2009.

[8] Mann, A., El Cid (DVD). Estados Unidos e Italia, Dear Film Produzione, Samuel Bronston Productions, 1961.

[9] Benioff, D. et al., Juego de Tronos (DVD). EE. UU. Home Box Office (HBO), Management 360, 2015. 